\title{
POSITIVE CHARGES CARRIED BY THE CANAL RAYS.
}

By L. W. Austin.

Experiments have been made by W. Wien ${ }^{a}$, Ewers $^{b}$, and Villard ${ }^{c}$ for detecting the positive charges carried by the canal rays of Goldstein by methods similar to those of Perrin ${ }^{d}$ for detecting the negative charges of cathode rays. Wien and Ewers conclude that the charges observed in a Faraday cylinder placed behind a perforated cathode were carried by the canal rays, while Villard holds that they are due to the slow diffusion of positive ions into the Faraday cylinder, basing his opinion on the observation that the positive charge first appeared some time after the canal rays began entering the cylinder, and in some cases only after the discharge had ceased. As has been pointed out by J. J. Thomson, ${ }^{e}$ this effect is very probably due to the fact that on account of the great conductivity of the gas produced by canal rays, the charge can not accumulate in the cylinder, but after the discharge ceases the gas recovers its insulating power and the cylinder can retain any charges which diffuse into it. If this view is correct, the positive charges in the cylinder, at least when observed electrometrically, are due mainly to diffusion and not to convection by the canal rays.

While almost all physicists must be satisfied from the work of W. Wien on the magnetic and electric deflections of canal rays that these rays carry a positive charge, the prominence given to the objections of Villard in recent publications ${ }^{a}$ make it desirable to publish the following direct experimental demonstration of the positive charges of the canal rays, which seems to be free from the objections just cited.

The plan of the experiment is somewhat similar to that of Ewers. The form of the tube is shown in figure 1. The discharge takes place

$a$ W. Wien: Wied. Ann. 65, p. 445; 1898.

$b$ Ewers: Wied. Ann. 69, p. 167; 1899.

$c$ Villard: J. de Phys. (3) 8, pp. 5 and 140; 1899.

$d$ Perrin: Comptes Rendus, 121, p. 1130; 1895.

e J. J. Thomson: Conduction of Electricity Through Gases, p. 521. 
entirely in the part $A$, which is $7 \mathrm{~cm}$ long and $2.5 \mathrm{~cm}$ in diameter. The diaphragms $d$, with openings $2 \mathrm{~mm}$ in diameter, form the cathode, and the canal rays pass through this into the part of the tube $B$. This is lined with brass netting, and at its center is placed a brass cylinder $c, 1.5 \mathrm{~cm}$ in diameter, with a $4 \mathrm{~mm}$ opening. This cylinder can be turned back out of the way, and is connected to earth through a galvanometer having a sensibility of $4 \times 10^{-8}$ amperes. The anode $e$ is con-

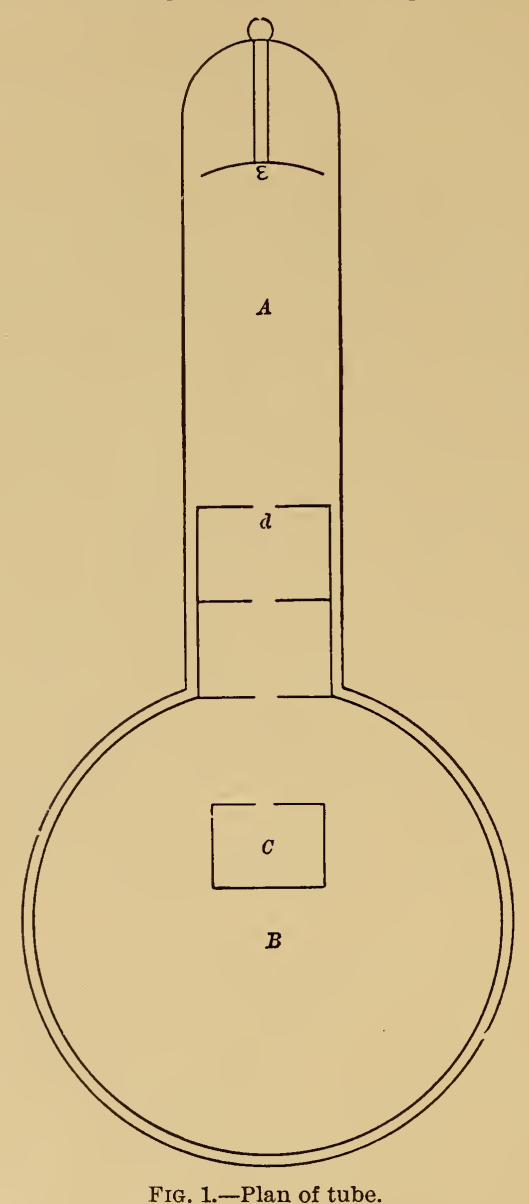

nected to one pole of an influence machine giving a current of about $0.0003 \mathrm{amp}$., the other pole of which, as well as the cathode $d$ and the brass net, are connected to earth. By this arrangement practically the whole of any charge imparted to the cylinder by the canal rays which enter it passes through the galvanometer to earth, as the resistance of the gas, even when highly ionized, is always very much greater than that of the galvanometer. 
With the cylinder in position to receive the rays, the galvanometer showed a positive deflection of about $300 \mathrm{~mm}$ as soon as the discharge was started; the deflection dropped at once to $5 \mathrm{~mm}$ when the cathode rays were deflected by a magnet, so that the canal rays could not pass the diaphragms. The original deflection appeared again as soon as the magnet was removed. When the cylinder was turned back so that the canal rays just grazed it as they passed through $B$, the deflection was about $15 \mathrm{~mm}$, probably due to diffuse rays from the main stream. The exact position of the rays could be easily determined by the bright fluorescence of the gas.

This experiment was performed with a potential difference between the electrodes of the tube of 8,000 volts, as measured on a Braun electrometer.

$a$ J. J. Thomson: loc. cit. E. Rutherford: Address before the International Congress of Arts and Sciences, St. Louis, 1904. G. C. Schmidt: Die Kathodenstrahlen, p. 110. 



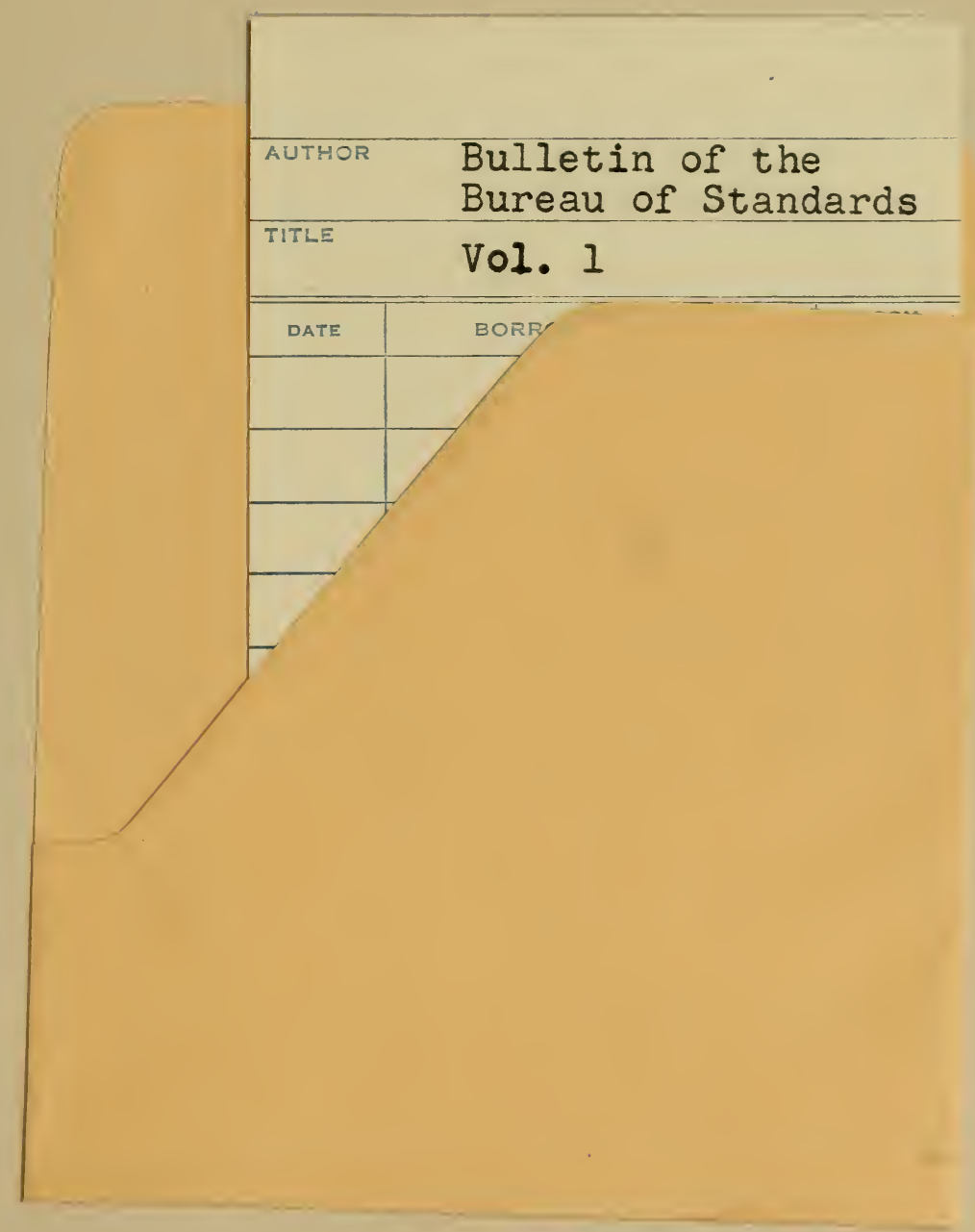


